\title{
Pospartum Spinal Osteoporoz: Bel Ağrısında Sıra Dışı Bir Neden
}

\author{
Postpartum Spinal Osteoporosis: An Uncommon Cause for Low Back Pain \\ Damla Cengiz, Eda Gürçay, Öznur Ecerkale, Alev Çevikol, Ajda Bal Hastürk, Aytül Çakcı \\ S. B. Ankara Dışkapı Yıldırım Beyazıt Eğitim ve Araştırma Hastanesi, Fizik Tedavi ve Rehabilitasyon Kliniği, Ankara, Türkiye
}

\section{Özet}

Postpartum spinal osteoporoz (PPSO) gebelikle ilişkili nadir görülen bir osteoporoz tablosudur. Genellikle ilk gebeliğin son üç aylık döneminde veya puerperal dönemde görülen bel, sırt ağrısı, vertebral kompresyon kııılarına bağlı boyda kısalma ve kifoz semptomları ile karakterizedir. Burada ilk gebeliğinden sonraki postpartum dönemde bel ağrısı ve vertebralarda kompresyon kırıkları olan bir olguyla PPSO tablosuna dikkat çekmeyi amaçladık. Gebelikle ilişkili PPSO, bel ağrısının sıra dışı, ender bir nedeni olmakla birlikte laktasyon dönemindeki kadının fiziksel ve psikolojik sağlığı ve yaşam kalitesi üzerindeki büyük etkisi, anne-bebek arasındaki ilişkinin gelişimi üzerine olası olumsuz etkileri nedeniyle ayrıcı tanıda göz önünde bulundurulmalıdır. (Türk Osteoporoz Dergisi 2014;20: 26-8)

Anahtar kelimeler: Gebelik, osteoporoz, bel ağrısı

\section{Summary}

Postpartum spinal osteoporosis (PPSO) is a rare form of osteoporosis related to pregnancy. It generally appears within the last trimester of pregnancy or postpartum period of the first child. The most common symptoms are low back pain, dorsalgia, loss of height due to vertebral compression fractures and kyphosis. Herein we aimed to draw attention to a case with PPSO, presenting with low back pain and vertebral fracures after postpartum period of the first child. While PPSO is an uncommon and rare disease, it should be considered in differential diagnosis of low back pain because of it's great impact on the physical and psychological health and on the quality of life of pregnant and lactating women and possible negative influence to the development of a normal relationship between mother and child. (Turkish Journal of Osteoporosis 2014;20: 26-8)

Key words: Pregnancy, osteoporosis, low back pain

\section{Giriş}

Postpartum Spinal Osteoporoz (PPSO) gebelik ile ilişkili, nadir görülen bir osteoporoz tablosudur. Hastalığın nadir görülmesi genellikle tanıda gecikmeye dolayısıyla hastaların doğru ve zamanında tedavi edilmemesine neden olabilir $(1,2)$. Illk kez 1948 yılında Albright ve Reifenstein geç gebelik döneminde ve laktasyonda spontan fraktürün olduğu bir olgu rapor etmiş $(3,4)$, 1955'de Nordin ve Roper 4 olguluk bir seri yayınlamıştır (5). Çalışmalar kısıtlı sayıda bildirilen olgular ile sınırlı olduğundan prevalansı bilinmemektedir. Literatürde 100 kadar vaka bildirilmiştir ve Türkiye'den sadece birkaç vaka rapor edilmiştir (3,6-12).

PPSO genellikle ilk gebeliğin son üç aylık döneminde (\%40) veya doğum sonrası puerperal dönemde (\%60) görülen bel, sırt ağrısı, vertebral kompresyon kırıklarına bağlı boyda kısalma ve kifoz semptomları ile karakterize bir hastalıktır. Patofizyolojisi günümüzde hala belirsizliğini koruduğu için tedavi protokolü de tam olarak tanımlanamamıştır $(1,11,13,14)$. Etiyolojinin gebelik sürecinin bir sonucu mu olduğu yoksa önceden var olan düşük kemik kitle düzeyi ile mi ilişkili olduğu konusu net değildir. Gebelik ve laktasyonda kemik döngüsü artar. Kemik mineral yoğunluğunun (KMY) azalmasının asıl nedeni büyük olasılıkla östrojenin kemik üzerindeki koruyucu etkisinin kaybına ve laktasyona eşlik eden hiperprolaktinemiye bağlıdır (15). Kemiği olumsuz etkileyen kalsitonin eksikliğine ilişkin izole raporlarda bulunmaktadır (16). Yüksek parathormon (PTH), artmış sitokin düzeyleri, düşük osteoblast aktivitesi, düşük kalsiyum alımı, vitamin D yetersizliği, gebelik sırasında steroid tedavisinin yanı sıra genetik yatkınlık suçlanan faktörlerdendir $(7,14)$.

Burada ilk gebeliğinden sonraki postpartum dönemde bel ağrısı ve vertebralarda kompresyon kırıkları olan bir olguyla bel ağrısının sıra dışı bir nedeni olan PPSO tablosuna dikkat çekmek amaçlanmıştır.

Yazışma Adresi/Address for Correspondence: Dr. Damla Cengiz, S. B. Ankara Dışkapı Yıldırım Beyazıt Eğitim ve Araştırma Hastanesi, Fizik Tedavi ve Rehabilitasyon Kliniği, Ankara, Türkiye Tel.: +90 3125962994 E-posta: damla_hcttpe@hotmail.com Geliş Tarihi/Received: 28.09.2013 Kabul Tarihi/Accepted: 14.01.2014

Türk Osteoporoz Dergisi, Galenos Yayınevi tarafından basılmıştır. / Turkish Journal of Osteoporosis, published by Galenos Publishing. 


\section{Giriş}

Postpartum Spinal Osteoporoz (PPSO) gebelik ile ilişkili, nadir görülen bir osteoporoz tablosudur. Hastalığın nadir görülmesi genellikle tanıda gecikmeye dolayısıyla hastaların doğru ve zamanında tedavi edilmemesine neden olabilir $(1,2)$. Illk kez 1948 yilında Albright ve Reifenstein geç gebelik döneminde ve laktasyonda spontan fraktürün olduğu bir olgu rapor etmiş $(3,4)$, 1955'de Nordin ve Roper 4 olguluk bir seri yayınlamıştır (5). Çalışmalar kısıtlı sayıda bildirilen olgular ile sınırlı olduğundan prevalansı bilinmemektedir. Literatürde 100 kadar vaka bildirilmiştir ve Türkiye'den sadece birkaç vaka rapor edilmiştir (3, 6-12).

PPSO genellikle ilk gebeliğin son üç aylık döneminde (\%40) veya doğum sonrası puerperal dönemde (\%60) görülen bel, sırt ağrısı, vertebral kompresyon kırıklarına bağlı boyda kısalma ve kifoz semptomları ile karakterize bir hastalıktır. Patofizyolojisi günümüzde hala belirsizliğini koruduğu için tedavi protokolü de tam olarak tanımlanamamıştır $(1,11,13,14)$. Etiyolojinin gebelik sürecinin bir sonucu mu olduğu yoksa önceden var olan düşük kemik kitle düzeyi ile mi ilişkili olduğu konusu net değildir. Gebelik ve laktasyonda kemik döngüsü artar. Kemik mineral yoğunluğunun (KMY) azalmasının asıl nedeni büyük olasılıkla östrojenin kemik üzerindeki koruyucu etkisinin kaybına ve laktasyona eşlik eden hiperprolaktinemiye bağlıdır (15). Kemiği olumsuz etkileyen kalsitonin eksikliğine ilişkin izole raporlarda bulunmaktadır (16). Yüksek parathormon (PTH), artmış sitokin düzeyleri, düşük osteoblast aktivitesi, düşük kalsiyum alımı, vitamin D yetersizliği, gebelik sırasında steroid tedavisinin yanı sıra genetik yatkınlık suçlanan faktörlerdendir $(7,14)$.

Burada ilk gebeliğinden sonraki postpartum dönemde bel ağrısı ve vertebralarda kompresyon kırıkları olan bir olguyla bel ağrısının sıra dışı bir nedeni olan PPSO tablosuna dikkat çekmek amaçlanmıştır.

\section{Olgu}

Yirmi üç yaşında kadın hasta, kliniğimize doğumdan 1,5 ay sonra başlayan ve 2 aydır devam eden, şiddetli bel ağrısı şikayetiyle başvurdu. Hasta yakından takip edilmek üzere kliniğimize yatırıldı. Özgeçmişinde ve soy geçmişinde özellik yoktu. Hastanın ilk doğumuydu ve bebeğini emziriyordu. Vücut kitle indeksi (VKi) 23,1 kg/m² idi. Ağrı sorgulaması görsel analog skalasına (VAS) göre 10 idi. Fizik muayenede lomber vertebra spinöz proçeslerinde hassasiyet, paravertebral kas spazmı, bel hareketlerinde özellikle ekstansiyon yönünde olmak üzere her yöne kısıtlılık ve ağrı vardı. Sakroiliak eklem muayenesi normaldi. İnspeksiyonla minimal torakal kifozu olduğu not edildi. Nörolojik muayene normaldi. Laboratuvar bulgularında PTH: 81,7 pg/ml (12-69), 25-OH vitamin D: 11,5 ng/mL (10-40) idi. Biyokimyasal testleri ve tiroid fonksiyon testleri normaldi. Torakal-lomber bölge manyetik rezonans görüntülemede T1112 seviyelerinde kompresyon kırıkları saptandı (Şekil 1). KMY ölçümünde; lomber bölge L2-4 total Z skor: -4.7 , femur boyun Z skor: $-3,8$ idi. Olgu PPSO olarak değerlendirildi. Hastanın emzirmeyi sonlandırması önerildi, D vitamini 300,000 IU/ay (3 ay süreyle), anti-rezorptif (risedronat $35 \mathrm{mg} / \mathrm{hf}$ ), kalsiyum 1200 mg/gün tedavileri ve ağrı için tramadol 50 mg/gün başlandı. Lumbosakral çelik balenli korse ile kısa süreli immobilizasyon sağlandı. Fizik tedavi programı olarak bel bölgesine sıcak paket (10 dk) ve transkutanöz elektriksel sinir stimulasyonu (15 dk) uygulandı, karın, bel, sırt ve pelvis çevresi kaslarını kuvvetlendirme egzersizleri ve postür egzersizleri toplam 10 seans süreyle uygulandı. Ağrısı progresif bir şekilde azalan ve VAS değerini 2 olarak ifade eden hasta bir ay sonra kontrole çağrılarak taburcu edildi.

\section{Tartışma}

Osteoporozun idiyopatik formları arasında, gebelik sırasında gelişen osteoporoz en az görülen ve üzerinde en az çalışılan formudur (9-11). Gebelikte \%65-\%72 oranında bel ve sırt ağrısına rastlanır, gebeliğin 6 . ayında başlar ve postpartum 6 . ay civarında sona erer $(6,16)$. Genellikle pelvis eklemlerinde, kaslarında ve ligamentlerinde oluşan fizyolojik ve biyomekanik değişikliklere sekonder olarak gelişen mekanik karakterdeki ağrıdır. Asıl belirleyiciler, daha önceki gebelikte bel ağrısı öyküsü olması ve multiparitedir. Ayrıca postural değişiklikler ve uterusun artan boyutlarına bağlı olarak da bel ağrısı gelişebilir $(6,11,12,16)$. Burada gebelik öncesi sağlıklı olan ve kemik metabolizmasını etkileyecek bir hastalığı bulunmayan bir olgunun laktasyon döneminde gelişen PPSO klinik tablosu sunulmuştur.

Doğum sonrası dönemde bel ağrılarının nadir bir nedeni olan PPSO'nun etiyolojisi tam olarak anlaşılamamış olsa da yetersiz beslenme, düşük kalsiyum alımı, düşük vücut ağılığı, ailede osteoporotik kırık öyküsü ve düşük vertebral KMY güçlü risk faktörleridir. Bu durum ağılıklı olarak ince yapılı, primigravid ve emziren kadınları etkiler $(1,11,17,18)$. KMY değerlerinde anlamlı azalmaya bağlı olarak travma olmaksızın vertebral farktürler görülebilir $(11,12,18)$. Özellikle vertebra skorları femur skorlarına göre daha düşüktür $(1-3,19)$. Bu risk faktörleri göz önüne alındığında hastamızın VKi normaldi ve ailesinde osteoporotik kırık öyküsü yoktu. Literatürle uyumlu olarak KMY değerleri osteoporotik, vertebra skorları femur skorlarına göre daha düşük ve torakal vertebralarda travma öyküsü olmadan gelişen kompresyon fraktürleri vardı.

PPSO'da laktasyon sırasında meme bezlerinden PTH ilişkili peptidin (PTHrP) artmış salgısı sonucu kemik rezorbsiyonu $\operatorname{artar}(2,15)$. PTHrP, 1- $\alpha$ hidroksilazı PTH kadar güçlü uyaramaz dolayısıyla 1,25 OH vitamin $D$ düzeyi düşer. Literatürdeki olgularda hiperkalseminin eşlik ettiği gözlense de hafif yükselmiş ALP dışında bir laboratuvar anormalliği gözlenmez $(11,18-20)$. Hastamızın D vitamini düzeyi düşük, PTH düzeyi yüksek, kalsiyum, fosfor ve ALP düzeyleri normal sınırlardaydı. Postpartum sakroileit tablosu bel ağrısına yol açabilir. Septik sakroileit ve inflamatuar sakroileitin bel ağrısına neden olduğu ve postpartum dönemde radiküler ağrı yarattığı literatürde rapor edilmiştir. Artmış eritrosit sedimentasyon hızı, ALP, lökositoz ve 
pozitif görüntüleme yöntemleri, klinik bulgularla birlikte tanıy destekler $(12,21)$. Hastamızda sakroiliak eklemler hassas değildi, kompresyon testleri negatifti ve laboratuvar parametrelerinde inflamasyon lehine bulgusu yoktu.

PPSO'nun mekanizması tam anlaşılmasa da tedavide primer koruma esastır. Primer koruma amacıyla düzenli egzersiz, dengeli beslenme ve profilaktik kalsiyum (600-1500 mg/gün) ve D vitamini (800-880 IU/gün) replasmanı ve iyileşme sürecini hızlandırması bakımından emzirmenin kesilmesi önerilmiştir. Antirezorptif ilaçlardan bifosfonat tedavisine erken başlandığında hastaların klinik bulgularında ve KMY değerlerinde anlamlı artış olduğu ve bu artışın lomber bölgede belirginleştiği gösterilmiştir. Fakat premenopozal kadınlarda etkinliği ve emziren veya tekrar gebelik istemi olan kadınlarda prenatal yan etkileri bilinmediğinden ayrıca kemikte birikici etkisi olduğundan uzun dönem güvenirliği bakımından kapsamlı çalışmalara ihtiyaç duyulmaktadır. Stronsiyum ranelat ile $K \mathrm{KY}^{\prime}$ 'de görülen düzelme ve eşlik eden bel ağrısında iyileşme olması, bifosfonatlara alternatif bir tedavi seçeneği olabileceğini ortaya koymuştur. Anabolik tedavi olarak teriparatid (PTH (1-34) peptidi) özellikle gelecekte gebelik düşüncesi olan hastalarda, bifosfonatlar gibi kemik matriksinde yıllarca birikmediği için bir tedavi seçeneği olarak önerilebilir $(2,12,20,22)$. Sadece emzirmeyi kesme ve kalsiyum, D vitamini replasmanı ile tedavi edilen olgularda 8-18. aylarda \%2-\%4; 2-4 yıllık sürede ise \%9,5 oranında lomber KMY'de artış gözlenmiştir. PPSO genellikle kendini sınırlayan bir durumdur ve sonraki gebeliklerde tekrarlama eğilimi göstermez $(1,20)$. Bizde benzer yaklaşımla hastadan emzirmeyi kesmesini istedik, kalsiyum, D vitamini ve bifosfonat tedavilerinin yan sıra kapsamlı bir fizik tedavi programı uyguladık, bu tedaviler eşliğinde hastanın şikayetleri geriledi.

Literatürde akut dönemde omurga immobilizasyonu ve ağı ile mücadele açısından kısa sureli korse kullanımını öneren çalışmalar mevcuttur. Bununla birlikte akut evrede ağrı kontrolünün korse yerine zayıf opioidler eklenerek yapılması da öneriler arasındadır $(20,23,24)$. Bu konuda yapılmış çalışmaların azlığı ve uzun süreli korse kullanımının yaptığı immobilizasyonun olumsuz etkileri göz önünde bulunulduğunda yararı tartışmalıdır. Hastamızda akut dönemde ağrıyı önlemek için zayıf opioid ve korse birlikte kullanılmıştır.

Gebelikle ilişkili özellikle ilk doğum sonrası gelişen PPSO, bel ağıısının sıra dışı, ender bir nedeni olmasına rağmen gebelik veya laktasyon dönemindeki kadının fiziksel ve psikolojik sağlığını ve yaşam kalitesini büyük oranda etkilediği, anne-bebek arasındaki ilişkinin gelişimi üzerine olası olumsuz etkileri nedeniyle ayrıcı tanıda göz önünde bulundurulmalıdır.

\section{Kaynaklar}

1. Kohlmeier L, Marcus R. Osteoporosis associated with pregnancy. In: Marcus R, Feldman D, Kelsey J (eds). Osteoporosis. San Diego: Academic Press; 2001. p. 341-9.

2. Joanna D, Wanda HS. Pregnancy associated osteoporosis-a case report. Ginekol Pol 2012;83:377-9.

3. O'Sullivan SM, Grey $A B$, Singh R, Reid IR. Bisphosphonates in pregnancy and lactation-associated osteoporosis. Osteoporosis Int 2006;17:1008-12

4. Davey MR, De Villiers JT, Lipschitz S, Pettifor JM. Pregnancy- and lactation-associated osteoporosis. JEMDSA 2012;17:149-53.

5. Nordin BE, Roper A. Post-pregnancy osteoporosis; a syndrome? Lancet 1955;1:431-4.

6. Colliton J. Managing back pain during pregnancy. Medscape Womens Health 1997:2:2.

7. Sarikaya S, Ozdolap S, Açıkgöz G, Erdem CZ. Pregnancy associated osteoporosis with vertebral fractures and scoliosis. Joint Bone Spine 2004;71:84-5.

8. Sarı H, Akarırmak U. Gebelikte osteoporoz. Osteoporoz Dünyasından 2000;6:129-33.

9. Özbek G, Reşorlu H, Karatepe AG, Kaya T, Günaydın R, Özer N, ve ark. Gebeliğe bağlı osteoporoz: Olgu sunumu. Osteoporoz Dünyasından 2006;12:39-42.

10. Ofluoglu O, Ofluoglu D. A case report: pregnancy-induced severe osyeoporosis with eight vertebral fractures. Rheumatol Int 2008:29:197-201

11. Gündüz B, Erhan B, Saridoğan $M$, Elbaşı N, Özdoğan $H$. Postpartum Spinal Osteoporosis: An Unusual Cause of Low Back Pain. Turk J Rheumatol 2010;25:47-9.

12. Tosun A, Fidan F, Alkan BM, Eroğlu EE, Ardıçoğlu Ö, Tosun Ö. Vertebral Fractures Due to Postpartum Spinal Osteoporosis: an Unusual Cause of Low Back Pain. Turkish Journal of Osteoporosis 2011;17:21-3.

13. Khovidhunkit W, Epstein S, Osteoporosis in pregnancy, Osteoporos Int 1996:6:345-54.

14. Bianchi ML. Osteoporosis during pregnancy. Eur Musculoskel Rev 2009:4:30-4.

15. Clarke B, Khosla S. Female reproductive system and bone. Arch Biochem Biophys 2010;50:118-28.

16. Kovacs C, El-Hajj Fuleihan G. Calcium and bone disorders during pregnancy and lactation. Endocrinol Metab Clin North Am 2006;35:21-51.

17. Di Gregorio S, Danilowicz K, Rubin Z, Mautalen C.Osteoporosis with vertebral fractures associated wih pregnancy and lactation. Nutrition 2000;16:1052-5.

18. Tran HA, Petrosvky N. Pregnancy-associated osteoporosis with hiperkalsemia. Intern Med J 2002;32:481-5.

19. Reid IR, Wattie DJ, Evans MC, Budary AA. Post-pregnancy osteoporosis associated with hipercalcaemia. Clin Endocrinol (Oxf) 1992:37:298-303.

20. Akyüz G, Bayındır Ö. Gebelik ile ilişkili Osteoporoz. Türk Fiz Tıp Rehab Derg 2013;59:145-50.

21. Pfeifer M, Begerow B, Mine HW. Effects of a new spinal orthesis on posture, trunk strength, and quality of life in women with postmenopausal osteoporosis: a randomized trial. Am J Phys Med Rehabil 2004;83:177-86

22. Hellmeyer L, Kühnert M, Ziller V, Schmidt S, Hadji P. The use of i.v. bisphosphonatein pregnancy associated osteoporosis case study. Exp Clin Endocrinol Diabetes 2007;115:139-42.

23. Liu XQ, Li FC, Wang JW, Wang S. Postpartum septic sacroiliitis misdiagnosed as sciatic neuropathy. Am J Med Sci 2010;339:292-5.

24. Yamaga A, Taga M, Takahashi T, Shirai T. A case of postpregnancy osteoporosis. Eur J Obstet Gynecol Reprod Biol 2000;88:107-9. 